\title{
A Homeopathic Combination Preparation in the Treatment of Feverish Upper Respiratory Tract Infections: An International Randomized Controlled Trial
}

\author{
Manuela Thinesse-Mallwit
a Private Practice, Munich, Germany;
${ }^{\mathrm{b} B o g o m o l e t s ~ N a t i o n a l ~ U n i v e r s i t y, ~ K i e v, ~}$ \\ , Ukraine; \\ ${ }^{c}$ Acomed Statistics, Leipzig, Germany; \\ ${ }^{\mathrm{d}}$ Deutsche Homöopathie-Union, Karlsruhe, Germany
}

\section{Keywords}

Upper respiratory tract infections - Common cold . Fever . Randomized controlled clinical trial . Homeopathy

\begin{abstract}
Summary
Background: Upper respiratory tract infections (URTI) are very common and associated with considerable healthcare costs. We evaluated the clinical benefit of a homeopathic add-on therapy. Patients and Methods: In this randomized controlled multinational clinical trial, patients (age range 1-65 years) with feverish URTI received either on-demand symptomatic standard treatment (ST group: paracetamol, ambroxol, and/or oxymetazoline), or homeopathic medication (IFC group: Influcid ${ }^{\circledR}$ ) for 7 days plus the same ondemand standard treatment. URTI symptoms were assessed using the Wisconsin Upper Respiratory Symptom Survey-21. Response at day 4, defined as absence of fever and absence or very mild degree of URTI symptoms, was the primary outcome measure. Results: 523 patients (265 IFC group, 258 ST group) were randomized in 12 Ukrainian and 10 German centers. The responder rate on day 4 was $15.4 \%$ in the IFC group and $6.7 \%$ in the ST group $\left(\Delta_{\mathrm{IFC}-\mathrm{ST}}=\right.$ $8.7 \%, 95 \%$ confidence interval $2.9-14.5 \%)$. The IFC group used less symptomatic medication, and symptoms were alleviated 1-2 days earlier. 3 and 8 adverse events (AEs) in the IFC and ST group, respectively, were assessed as possibly treatment-related; 2 out of the 3 AEs in the IFC group were possibly related to symptomatic therapy, 1 (vomiting) to IFC treatment. Conclusion: The homeopathic treatment shortened URTI duration, reduced the use of symptomatic medication, and was well tolerated.
\end{abstract}

\author{
Schlüsselwörter \\ Oberer Atemwegsinfekt - Grippaler Infekt - Fieber . \\ Randomisierte kontrollierte klinische Prüfung . \\ Homöopathie
}

\section{Zusammenfassung}

Hintergrund: Obere Atemwegsinfekte (OAWI) sind sehr häufig und verursachen erhebliche Krankheitskosten. Wir untersuchten den klinischen Nutzen einer homöopathischen Zusatztherapie. Patienten und Methoden: Randomisierte, kontrollierte, multinationale klinische Prüfung. Patienten (1-65 Jahre) mit fiebrigem OAWI erhielten entweder bei Bedarf eine symptomatische Standardbehandlung (Paracetamol, Ambroxol und / oder Oxymetazoline; ST-Gruppe) oder für 7 Tage ein homöopathisches Arzneimittel (Influcid ${ }^{\circledR}$; IFCGruppe) plus die gleiche bedarfsorientierte Standardbehandlung. OAWI-Symptome wurden mittels Wisconsin Upper Respiratory Symptom Survey-21 bestimmt. Primärer Endpunkt war die Ansprechrate an Tag 4, definiert als Fieberfreiheit sowie keine oder nur sehr milde OAWI-Symptome. Ergebnisse: 523 Patienten (265 IFC-Gruppe, 258 ST-Gruppe) wurden in 12 ukrainischen und 10 deutschen Zentren randomisiert. Die Ansprechrate an Tag 4 lag bei 15,4\% in der IFCGruppe und $6,7 \%$ in der ST-Gruppe $\left(\Delta_{\mathrm{IFC}-\mathrm{ST}}=8,7 \%\right.$, 95 $\%$-Konfidenzintervall 2,9-14,5\%). Die IFC-Gruppe benötigte weniger symptomatische Medikation, und die Symptome besserten sich 1-2 Tage früher. Für 3 bzw. 8 unerwünschte Ereignisse (UE) in der IFC- bzw. ST-Gruppe wurde ein möglicher Kausalzusammenhang zur Behandlung hergestellt. 2 der 3 UEs der IFC-Gruppe wurden mit der symptomatischen Behandlung und 1 UE (Erbrechen) mit der IFC-Behandlung assoziiert. Schlussfolgerung: Die homöopathische Behandlung verkürzte die OAWI-Dauer, verringerte den Bedarf an symptomatischer Medikation und wurde gut vertragen. 


\section{Introduction}

Upper respiratory tract infections (URTI) or common colds represent the most frequently occurring illness in the world, and are a leading cause of missed days from work and school. They cause considerable direct and indirect healthcare costs, and the economic burden is a major public health challenge [1]. Colds typically afflict most adults and adolescents 2-4 times a year, while young children may have as many as 6-8 or even more episodes [2-4]. The most common symptoms are sore throat, runny nose, general malaise, and low-grade fever at onset, followed by nasal congestion and cough. Symptoms usually peak around day 3 or 4 and last 1-2 weeks with a median of 7 days $[5,6]$. The majority of URTI are caused by viral pathogens, most commonly rhinoviruses [2, 7-9], but also influenza viruses [10].

There is no approved specific therapy for URTI, treatment is therefore mainly symptomatic [11]. The most common pharmacological treatments are antipyretics, anti-inflammatory drugs, expectorants, decongestants, and cough suppressants, either alone or in combination. Supportive measures can include bed rest, hot baths, inhalations, gargling, and drinking plenty of fluids [6]. Antibiotics are widely prescribed, but often inappropriate because URTI are mostly caused by viruses [11]. Antibiotics are only indicated in the case of bacterial infection, i.e. streptococci, and to pre- vent superinfections $[12,13]$; overuse can lead to the development of community-acquired resistant pathogens which are an increasing and serious health burden [14].

Homeopathy has become increasingly popular [15]. Safe and effective therapies would be a welcome addition to conventional treatment, especially because numerous conventional medicines are not authorized for use in small children. Homeopathy has a tradition of more than 200 years, and its main therapeutic objective is to stimulate the self-healing power of the body. The investigated homeopathic preparation (Influcid ${ }^{\circledR}$ (IFC), Deutsche HomöopathieUnion, DHU, Karlsruhe, Germany) was launched in its first form in Germany in 1928, and is currently available in 22 countries worldwide. It contains a fixed combination of 6 homeopathic single substances which address a broad spectrum of URTI symptoms. Preliminary studies suggest it is effective and safe in the treatment of typical cold-related symptoms in both adults and children [16, 17].

Since conventional therapy of URTI is not always effective and sometimes leads to side effects and inappropriate use of antibiotics, a search for safe and effective further treatment options is justified. We therefore aimed to evaluate the effectiveness and safety of IFC as an add-on to symptomatic standard treatment of URTI. Published methodologies for trials investigating the treatment of influenza with homeopathic medicinal products have been considered [18, 19].
Table 1. Eligibility criteria

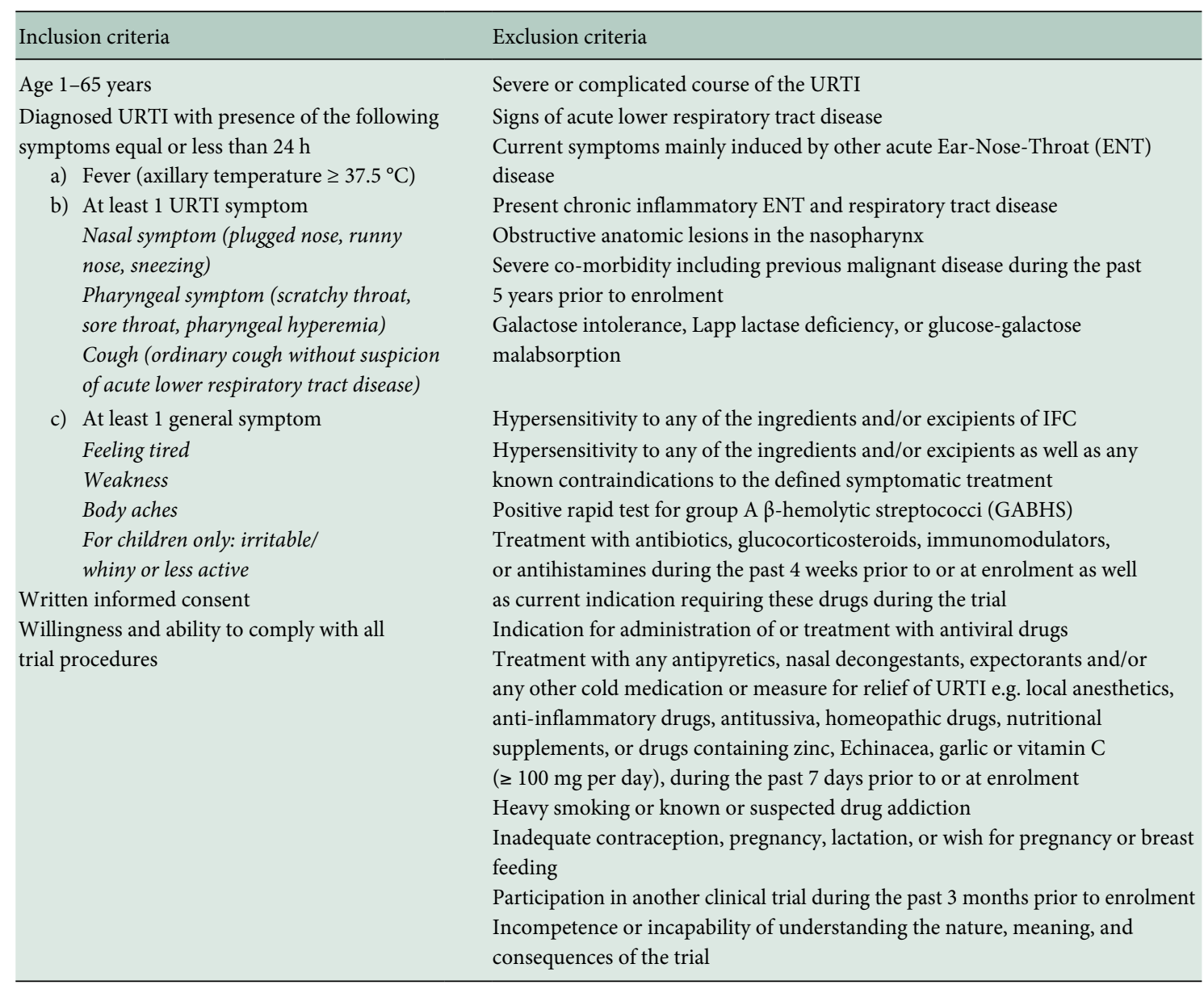


Table 2. Comparison of demographic, clinical, and other relevant characteristics, intention-to-treat (ITT) analysis

\begin{tabular}{|c|c|c|}
\hline Characteristics & IFC group, $\mathrm{n}=261$ & ST group, $\mathrm{n}=256$ \\
\hline \multicolumn{3}{|l|}{ Age, median (P25, P75), years } \\
\hline Children $(<12$ years $)$ & $4.0(3.0,7.0)$ & $5.0(3.0,7.0)$ \\
\hline Adults/adolescents ( $\geq 12$ years) & $33.0(20.0,45.0)$ & $33.0(22.0,43.0)$ \\
\hline Sex, male/female ${ }^{\mathrm{a}}, \mathrm{n}(\%)$ & $104(40) / 157(60)$ & $118(46) / 138(54)$ \\
\hline \multicolumn{3}{|l|}{ Height, median (P25, P75), cm } \\
\hline Children (< 12 years) & $110(98,126)$ & $111(97,128)$ \\
\hline Adults/Adolescents ( $\geq 12$ years) & $168(162,175)$ & $170(164,178)$ \\
\hline \multicolumn{3}{|l|}{ Weight, median (P25, P75), kg } \\
\hline Children $(<12$ years $)$ & $19.3(15.0,25.0)$ & $19.0(14.8,25.0)$ \\
\hline Adults/Adolescents ( $\geq 12$ years) & $68.0(58.0,80.0)$ & $71.1(60.0,84.0)$ \\
\hline \multicolumn{3}{|l|}{ Influenza test results (PCR analysis), $\mathrm{n}(\%)^{\mathrm{a}}$} \\
\hline Influenza $\mathrm{A}$ and $\mathrm{B}$-negative & $227(87)$ & $219(86)$ \\
\hline Influenza A-positive & $19(7)$ & $31(12)$ \\
\hline Influenza B-positive & $12(5)$ & $6(2)$ \\
\hline Body temperature at baseline, mean (SD), ${ }^{\circ} \mathrm{C}$ & $38.0(0.4)$ & $38.0(0.4)$ \\
\hline \multicolumn{3}{|l|}{ Main URTI symptoms at baseline, $\mathrm{n}(\%)^{\mathrm{a}}$} \\
\hline Mucosal hyperemia & $237(91)$ & $228(89)$ \\
\hline Nasal breathing impairment & $223(85)$ & $229(90)$ \\
\hline Ability to perform daily activities & $196(75)$ & $209(82)$ \\
\hline Nasal symptoms & $231(89)$ & $240(94)$ \\
\hline Pharyngeal symptoms & $240(92)$ & $232(91)$ \\
\hline Cough & $194(74)$ & $208(81)$ \\
\hline Feeling tired & $257(98)$ & $249(97)$ \\
\hline Weakness & $252(97)$ & $248(97)$ \\
\hline Body aches & $208(80)$ & $208(81)$ \\
\hline Irritable/whiny ${ }^{\mathrm{b}}$ & $114(88)$ & $114(87)$ \\
\hline Less active $\mathrm{e}^{\mathrm{b}}$ & $125(96)$ & $126(96)$ \\
\hline WURSS-21 total score at baseline, mean (SD) & $71.4(24.7)$ & $74.4(25.5)$ \\
\hline
\end{tabular}

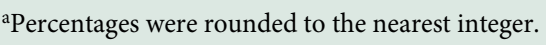

${ }^{b}$ Assessed in children below 12 years of age only (in total 261 patients were $<12$ years, thereof 130 and 131 patients in the IFC and ST group, respectively).

$\mathrm{PCR}=$ Polymerase chain reaction; $\mathrm{SD}=$ standard deviation .

\section{Methods}

A randomized, standard treatment (ST)-controlled, parallel groups, open, multicenter, multinational clinical trial was conducted in accordance with ICH guidelines for Good Clinical Practice and met the standards of the Declaration of Helsinki. Patients were recruited from November 2010 to April 2011 in 12 centers in the Ukraine (4 general practitioners and 8 pediatricians) and 10 centers in Germany (4 general practitioners and 6 pediatricians) following approval by the appropriate ethical committee and competent authority. The trial was registered in the ISRCTN study register prior to patient inclusion (No: ISRCTN60440500).

Pediatric and adult patients presenting with clinical signs and symptoms of an URTI with a duration of up to $24 \mathrm{~h}$, accompanied by fever $\geq 37.5^{\circ} \mathrm{C}$ (axillary temperature), were screened for eligibility. Table 1 gives an overview of the full inclusion and exclusion criteria.

Eligible patients who provided informed consent were randomized to receive either on-demand symptomatic standard treatment (ST group: paracetamol, ambroxol, and/or oxymetazoline), or the same symptomatic standard treatment plus IFC (IFC group) as an add-on treatment for 7 days. Randomization took place centrally in blocks of 4 using SAS version 9.1 (SAS Institute Inc., Cary, NC, USA) for random sequence generation. Eligible patients were sequentially allocated a patient number in ascending order based on entry in the trial. This procedure ensured proper concealment of treatment allocation. For an age-stratified inclusion ( $<12$ or $\geq 12$ years), randomization faxes were used to track the age of included subjects, and recruitment was stopped when the target number of subjects in the defined age group was reached.

Patients filled out a diary and took their axillary body temperature several times daily. They were seen and assessed by the investigator during the baseline visit (day 1 ), on day 4 , day 8 , and day 15 , and additionally received a follow-up call on day 2 and day 3 . IFC tablets containing a fixed combination of the following homeopathic single substances were used (number behind the ' $\mathrm{D}$ ' represents the number of decimal dilution steps): Aconitum ('monkshood') D3, Bryonia ('red or white bryony') D2, Eupatorium perfoliatum ('boneset') D1, Gelsemium ('yellow jasmine') D3, Ipecacuanha ('ipecac') D3, and Phosphorus D5. During the first $72 \mathrm{~h}$, adolescents ( $\geq 12$ years) and adults were instructed to orally take 12 tablets a day ( 1 tablet every hour), and children ( $<12$ years) 8 tablets per day ( 1 tablet every $2 \mathrm{~h}$ ); during the following $96 \mathrm{~h}$, adolescents and adults took 2 tablets 3 times daily, and children 1 tablet 3 times daily. Paracetamol syrup, ambroxol syrup, and oxymetazoline nasal spray were offered as symptomatic standard medication (respectively as an antipyretic, expectorant, and nasal decongestant) to all patients based on an 'as-needed' basis.

The primary objective was to evaluate the effectiveness and safety of IFC as an add-on to symptomatic standard treatment of URTI. The primary outcome measure was 'treatment response' which was defined as a combination of i) mean axillary body temperature $\leq 37.2^{\circ} \mathrm{C}$ on day 4 , and ii) absence or very mild degree of symptoms. URTI symptoms were assessed using the Wisconsin Upper Respiratory Symptom Survey 21 (WURSS-21) which is a 21-item illness- 


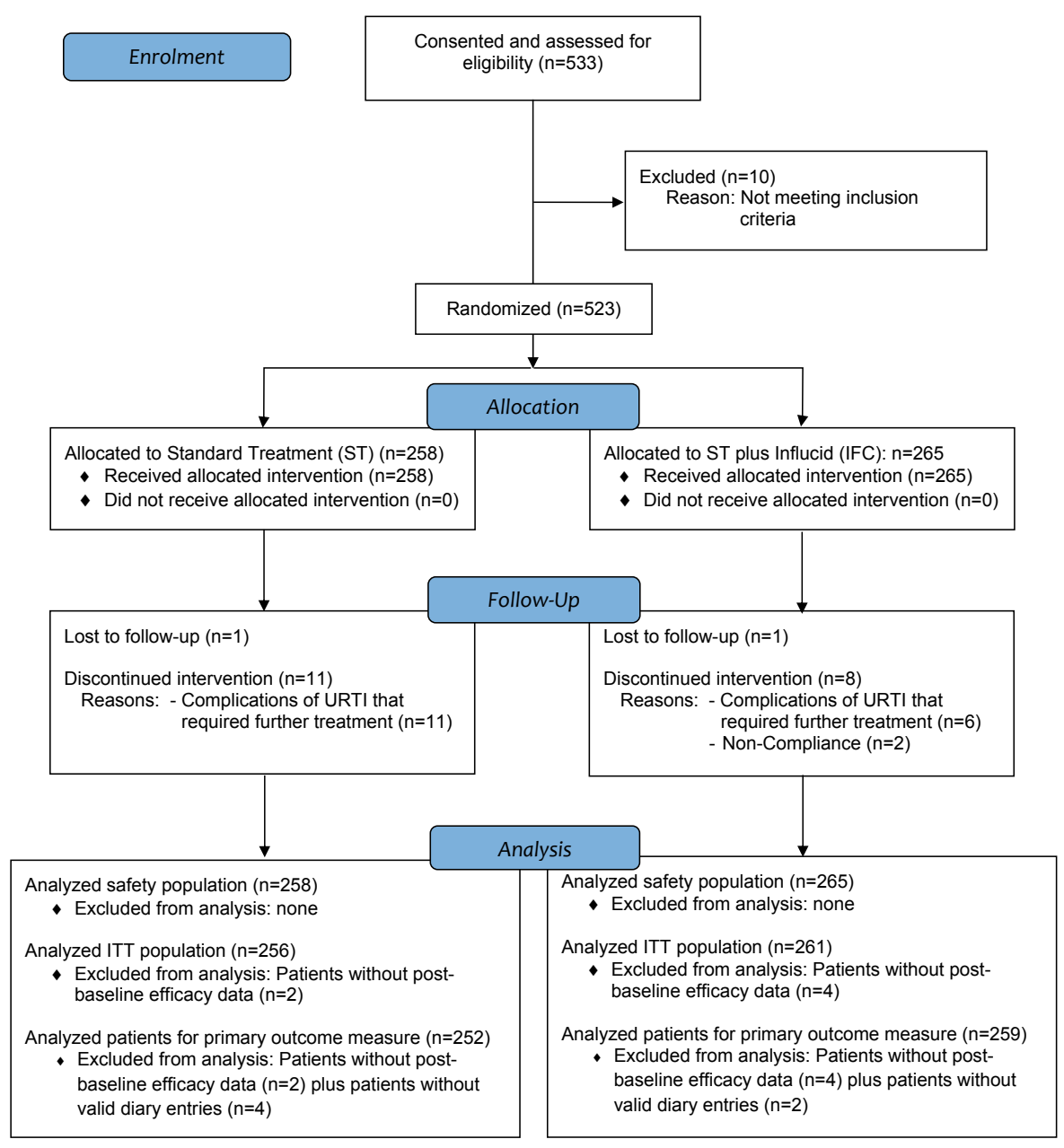

Fig. 1. Flow chart of patients.

had at least 1 post-baseline efficacy assessment. Additionally, a per-protocol analysis was performed. Safety analyses included all randomized patients. The last observation carry forward procedure was applied in the case of missing data including premature withdrawal from the trial. Treatment response was analyzed using the $\chi^{2}$ Test. The Mann-Whitney U (MWU) test was applied for explorative between-group analyses. Treatment-related differences were further presented as Hodges-Lehmann (HL) estimates of location shift and their 95\% confidence intervals (CI). The type I error level (alpha) was set at 0.05 . No adjustment was made for testing multiple secondary outcomes; it was therefore taken into consideration that some significant findings were expected to occur by chance. The interpretation of the exploratory analyses was principally based on the level of consistency with the results of the primary analyses.

\section{Results}

\section{Participants}

A total of 523 patients were randomized (223 in Germany, 300 in the Ukraine). The ITT population consisted of 261 patients in the IFC group ( $130<12$ years, $131 \geq 12$ years) and 256 in the ST group ( $131<12$ years, $125 \geq 12$ years). Figure 1 shows the flow and follow-up of patients in the trial.

Baseline demographic and clinical characteristics of patients were similar in both treatment groups (table 2). The influenza test results indicated that only $14 \%$ of the URTI cases were associated with an influenza virus infection. 
Table 3. Secondary outcome measures, intention-to-treat (ITT) analysis

\begin{tabular}{|c|c|c|c|c|}
\hline Outcome measure & IFC group, $n=261$ & ST group, $\mathrm{n}=256$ & Test, statistics ${ }^{\mathrm{a}}$ & $\mathrm{p}$ value \\
\hline Time to symptom alleviation assessed by WURSS item $1^{\mathrm{b}}$, days & 6.6 & 8.5 & $Z=-6.30$ & $<0.0001$ \\
\hline Resumption of normal daily activity ${ }^{\mathrm{c}}$ at $1^{\text {st }}$ follow-up visit (day 4$), \mathrm{n}(\%)$ & $94 / 196(48.0)$ & $58 / 209(27.8)$ & $\square^{2}(1)=17.62$ & $<0.001$ \\
\hline \multicolumn{5}{|l|}{ Symptom severity, median (P25, P75), n (\%) } \\
\hline WURRS-21 total score AUC & $643.5(395,952)$ & $928.0(597,1,312)$ & $Z=-5.67$ & $<0.001$ \\
\hline WURRS-21 symptom score (items 2-11) AUC & $304.0(197,453)$ & $425.0(290,611)$ & $Z=-5.81$ & $<0.001$ \\
\hline WURRS-21 quality of life score (items 12-20) AUC & $342.0(192,524)$ & $484.0(285,710)$ & $Z=-4.99$ & $<0.001$ \\
\hline \multicolumn{5}{|l|}{ Symptomatic medication use ${ }^{\mathrm{d}}$ (paracetamol, ambroxol, oxymetazoline) } \\
\hline Patients with any symptomatic drug use, $\mathrm{n}(\%)$ & $222 / 259(85.7)$ & $247 / 252(98.0)$ & $\square^{2}(1)=25.62$ & $<0.001$ \\
\hline Duration of symptomatic drug use, median (P25, P75), days & $6(4,9)$ & $9(7,12)$ & $Z=-7.12$ & $<0.001$ \\
\hline Paracetamol total amount, median (P25, P75), mg & $600.0(0,2,200)$ & $1,750.0(400,1,750)$ & $Z=-6.22$ & $<0.001$ \\
\hline Ambroxol total amount, median (P25, P75), mg & $112.5(0,390)$ & $315.0(113,630)$ & $Z=-5.91$ & $<0.001$ \\
\hline Oxymetazoline total amount, median (P25, P75), $\square \mathrm{g}$ & $292.5(0,675)$ & $720.0(253,1,080)$ & $Z=-6.39$ & $<0.001$ \\
\hline \multicolumn{5}{|l|}{ Axillary temperature $^{\mathrm{e}}$ (absence of fever), $\mathrm{n}(\%)$} \\
\hline $2^{\text {nd }}$ follow-up visit (day 8 ) & $251 / 259(96.9)$ & $235 / 252(93.3)$ & $\square^{2}(1)=3.67$ & 0.055 \\
\hline \multicolumn{5}{|l|}{ Hyperemia of oral mucosa ${ }^{\mathrm{e}}, \mathrm{n}(\%)$} \\
\hline $1^{\text {st }}$ follow-up visit (day 4$)$ & $188 / 261(72.0)$ & $208 / 256(81.3)$ & $\square^{2}(1)=6.13$ & 0.013 \\
\hline $2^{\text {nd }}$ follow-up visit (day 8) & $55 / 259(21.2)$ & $96 / 252(38.1)$ & $\square^{2}(1)=17.44$ & $<0.001$ \\
\hline \multicolumn{5}{|l|}{ Nasal breathing impairment $\mathrm{e}^{\mathrm{e}}, \mathrm{n}(\%)$} \\
\hline $1^{\text {st }}$ follow-up visit (day 4$)$ & $169 / 261(64.8)$ & $208 / 256(81.3)$ & $\square^{2}(1)=17.82$ & $<0.001$ \\
\hline $2^{\text {nd }}$ follow-up visit (day 8) & $68 / 259(26.3)$ & $111 / 252(44.0)$ & $\square^{2}(1)=17.77$ & $<0.001$ \\
\hline
\end{tabular}

\section{Efficacy Analysis}

The first primary response criterion, the percentage of patients who were free of fever at day 4 , was significantly higher in the IFC group compared to the ST group (76.8\% IFC vs. $56.7 \%$ ST; $\mathrm{p}<0.001)$. The second primary response criterion, the percentage of patients with WURSS-21-assessed absence or very mild degree of symptoms at day 4, was also significantly higher in the IFC group compared to the ST group (17.0\% IFC vs. $7.5 \%$ ST; $\mathrm{p}=0.0012$ ). The primary endpoint, occurrence of 'treatment response' defined as fulfilment of both primary response criteria at day 4, was significantly higher in the IFC group (15.4\%) compared to the ST group $(6.7 \%)\left(\Delta_{\mathrm{IFC}-\mathrm{ST}}=8.7 \%, 95 \%\right.$ CI $\left.2.9-14.5 \%\right)$. The per-protocol analysis confirmed the results of the ITT analysis (data not shown).

Use of symptomatic drugs was comparable between treatment groups in the 'treatment response' (at day 4) subgroup. In the 'nontreatment response' subgroup, the use of symptomatic drugs was higher in the ST group.

The between-group differences in percentages of patients with 'treatment response' throughout the 14-day study period are given in figure 2. This figure further illustrates the more prompt occurrence of 'treatment response' in the IFC group. The observed difference became statistically significant at day $4\left(\Delta_{\text {IFC-ST }}=8.7 \%\right)$, peaked at day 7 ( $\Delta_{\text {IFC-ST }}=28.9 \%, 95 \%$ CI $\left.20.3-37.6 \%\right)$, and continued until day $11\left(\Delta_{\text {IFC-ST }}=10.0 \%, 95 \%\right.$ CI $\left.2.4-7.7 \%\right)$.

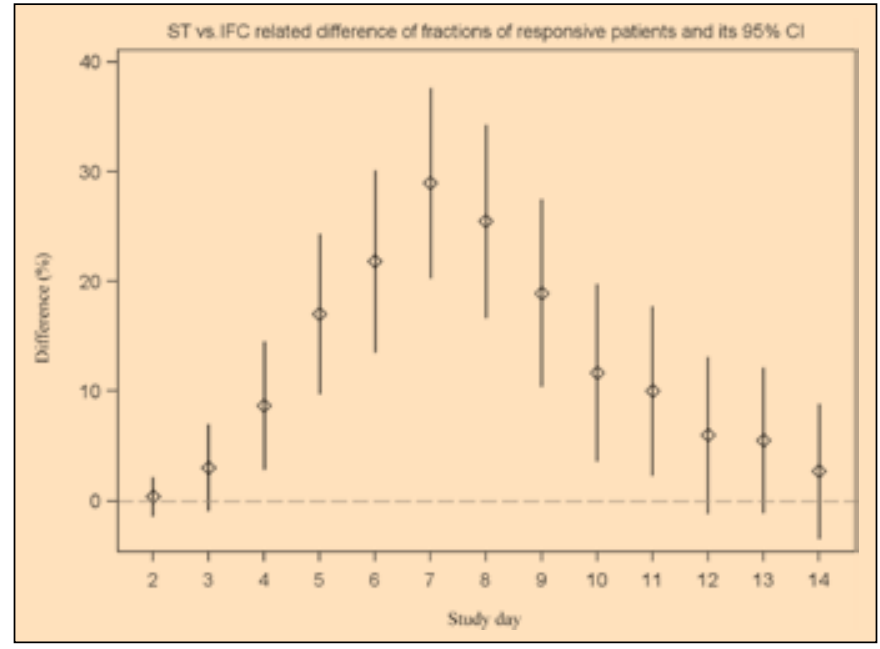

Fig. 2. Between-group differences in the percentage of treatment responders (IFC minus ST) by study day (including 95\% CIs).

Analysis of further secondary outcome measures (table 3) was consistent with the analysis of the primary outcome measure: The time to symptom alleviation as assessed by the first WURSS item was 1-2 days shorter in the IFC group (MWU: $Z=-6.30, p<0.0001$; HL: $\Delta_{\text {IFC-ST }}=-2$ days, $95 \%$ CI -2 to -1 days). Figure 3 displays the cumulated percentages of patients with symptom alleviation by 
Table 4. Resolution of WURSS-21 single items (2-20) and additional complaints, intention-to-treat (ITT) analysis

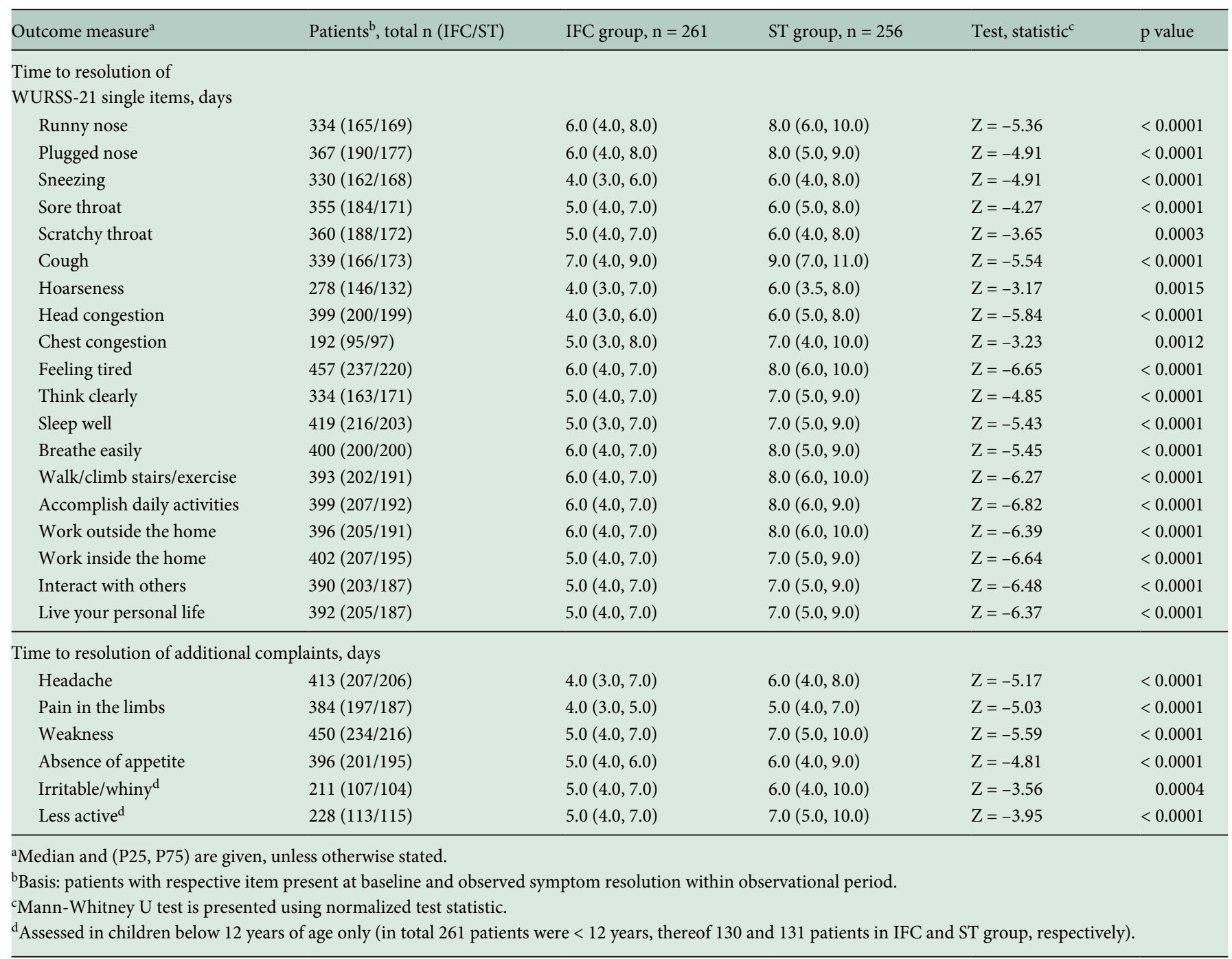

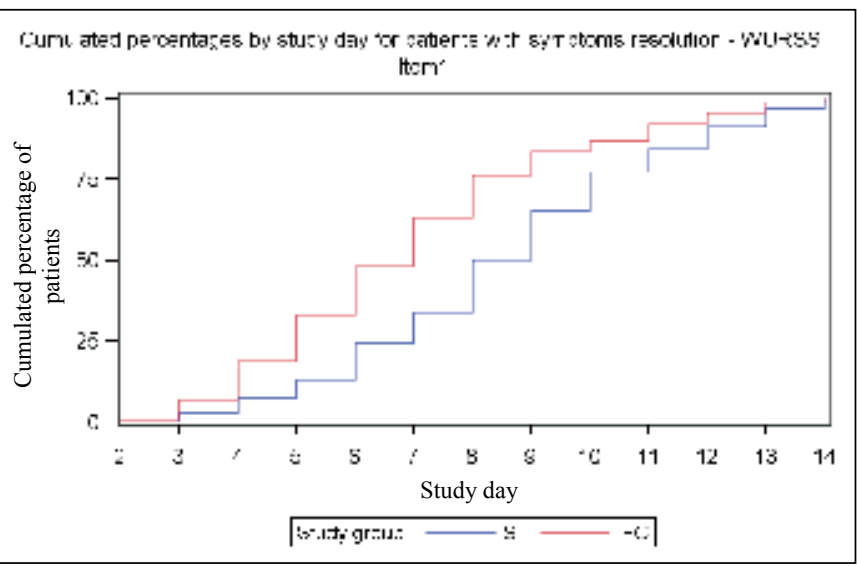

Fig. 3. Cumulated percentages by study day for patients with symptom alleviation as assessed by first WURSS item.

study day. The proportion of patients that resumed normal activity at first follow-up visit was $20 \%$ higher in the IFC group (48\% IFC vs. $28 \%$ ST). The AUC values of total WURSS-21 score and the subscores denoted a significantly lower median disease severity in IFC group during the observation period. Consistently, individual symptoms- and quality of life aspects-related impairment as measured by single WURSS-21 items (2-20) and additional complaints questions resolved significantly earlier in IFC group compared to ST group (table 4). Fewer patients consumed lower quantities of symptomatic drugs and stopped symptomatic intake earlier in the IFC group. The percentage of patients with absence of fever was $14 \%$ higher at first follow-up visit in the IFC group (82.4\% IFC vs. $68.8 \% \mathrm{ST}$ ), but not significantly higher on second follow-up visit when the fever had subsided in more than $90 \%$ of patients. Hyperemia and nasal breathing impairment were statistically significantly less at the first and second follow-up in the IFC group.

More than $90 \%$ of patients complied with the investigator's prescribed acute and maintenance treatment regimens.

\section{Safety Assessment}

Of 523 patients, $64(12.2 \%)$ experienced at least $1 \mathrm{AE}$ during the trial, $29 / 265$ (10.9\%) patients in the IFC group and 35/258 (13.6\%) patients in the ST group. A total of 85 single AEs were observed. All AEs were assessed as non-serious. For 3 AEs in the IFC group, 
the causal relationship was assessed as 'possible'; 2 cases (upper abdominal pain, asthenia) possibly related to symptomatic therapy; 1 case (vomiting) possibly related to IFC. 8 AEs (nausea $(n=2)$, diarrhea, dry mouth, gastro-esophageal reflux disease, nasal dryness, rash, visual impartment), experienced by 7 patients in the ST group were considered probably or possibly drug-related. 2 AEs (both in the IFC group) were of severe intensity but judged to be unrelated to the medication taken; the remaining 83 AEs were mild to moderate. $6(2.3 \%)$ patients in the IFC group and $11(4.3 \%)$ patients in the ST group were withdrawn from the study due to AEs classified as complications which needed to be treated with antibiotics, glucocorticosteroids, immunomodulators, antihistamines, or antiviral drugs.

\section{Discussion}

\section{Main Findings}

The use of IFC as an add-on treatment improved response, shortened the duration of URTI, reduced the use of symptomatic medication, and lowered the disease severity. Overall, the results suggest that IFC enhanced the self-recovery of the patients, and partly substituted the need for conventional symptomatic treatment. The results confirmed that IFC is well tolerated.

\section{Strengths and Limitations of this Study}

The study was randomized, and care was taken to ensure the concealment of random allocation. A very broad population ranging from pediatric patients to adults was included. Due to the exclusion of bacterial URTI, this study included the population where the need for further treatment options is greatest. Identification and demarcation of influenza virus-caused URTI enabled a further delineation of the study population.

A further strength of this trial is the large number of patients included, which increases the precision of the estimates. This study has a high external validity because its design is representative for routine clinical practice where the choice would be to offer IFC as an add-on treatment or not.

A limitation of this study was the absence of blinding to the treatment allocation, which could have led to a performance bias. Even though the primary outcome assessment was partly based on objective measures such as the absence of fever, it cannot be excluded with certainty that in particular the subjective outcome measures in the IFC group have been overestimated relative to the ST group. Similarly, the prescription of symptomatic medication at the discretion of the physician may have been affected by the lack of blinding. We tried to reduce this influence by providing the symptomatic medication to all patients as part of the investigational medicinal products, so there were no operational betweengroup differences. It could be argued that blinding could have been addressed by giving an indistinguishable placebo to the control group. We chose not to do so because we aimed to reflect usual practical care as closely as possible. The inclusion of a placebo would have implied IFC administration under the uncertainty of having a $50 \%$ chance of actually receiving a placebo. It has been demonstrated in the area of depression that the possibility of receiving placebos in clinical trials can affect outcomes [21]. There are still many unanswered questions about the effects of the probability of receiving placebo in clinical trials in other clinical domains, including URTI. If we were to have chosen a placebo-controlled design as referred to above, the implication could have been a difference in the effect of IFC of an unknown nature, making the trial less representative of usual care. A further, more general argument in favor of our choice of design, is that leading complementary and alternative medicine (CAM) researchers have argued that a different framework which places more emphasis on 'effectiveness research' - rather than efficacy research - is needed for CAM treatments with a long tradition of use such as homeopathy [22]. Our study fits well within this framework.

\section{Interpretation of Findings in Relation to Previous Publications and Implications for Future Research}

The current trial evidence on the homeopathic treatment of URTI is concerning the prevention of URTI $[23,24]$ and the treatment of chronic recurrent URTI [25-27]. Moreover, there exists evidence for other conditions that can include URTI [28-30] and for the treatment of acute cough, which can occur as part of URTI [31]. The treatments investigated are various specific products as well as individualized homeopathic treatment. In addition, we identified 3 non-controlled studies: 1 of individualized homeopathic treatment of chronic URTI [32], 1 of a combination product to treat the common cold [33], and 1 comparative cohort study which showed that homeopathically managed patients had significantly lower consumption of antibiotics compared to conventionally managed patients whilst achieving comparable clinical outcomes [34]. Therefore, the specific evidence base on the treatment of acute URTI is limited, but the available evidence is promising.

The 6 single homeopathic ingredients of IFC have a long tradition in the treatment of flu-like infections and URTI. In its original form as a solution, the effectiveness and safety of IFC (German name: Nisylen ${ }^{\circledR}$ ) was demonstrated in an open study including 94 patients in the treatment URTI [16]. In a multicenter open study including a total of 600 patients [17] (333 adults, 267 children) with URTI, an improvement was noted in about $90 \%$ of patients after 3 days. Another study compared the effectiveness of IFC in children aged 3-6 years with URTI to a cohort of children treated with symptomatic medication [35]. In the IFC group, clinical symptoms declined significantly earlier. However, allocation to treatment in this study was not randomized. Whilst the above studies are promising, a limitation is the absence of an adequate control group, which is why we conducted the current study.

Follow-up trials should assess primary outcomes on fever and symptoms after 4-7 days because this provides an optimum time frame to demonstrate enhanced recovery on homeopathic medicines within the context of a self-limiting disease such as URTI. Further controlled studies to investigate and confirm the role of homeopathic medicinal products in the treatment of URTI are warranted. 


\section{Conclusion}

In the study group using the homeopathic medicinal product IFC as an add-on to standard conventional treatment, a shorter duration of URTI was observed, less conventional symptomatic medication was used, and good tolerability was reported. Whilst further confirmatory studies are needed, this study indicates that an IFC treatment can make a positive contribution to the management of URTI.

\section{Acknowledgment}

We thank all investigators and patients who participated in this study and $\mathrm{R}$. van Haselen for his assistance in preparing the publication manuscript. The research support of Y. Aydin-Yavuz and S. De Jaegere (Karlsruhe); I. Borzenko, D. Kobyshcha, and I. Semenchuk (Kiev); S. Weber (Magdeburg); N. Gmeinwieser, T. Huber, and R. Piller (Munich) is gratefully acknowledged.

\section{Disclosure Statement}

MT and VM received an advisory fee for coordinating the study. TK received a fee from Deutsche Homöopathie-Union for his contribution in the study. PK is an employee of Deutsche Homöopathie-Union.

\section{References}

1 Heikkinen T, Järvinen A: The common cold. Lancet 2003;361:51-59.

2 Gwaltney JM: Viral respiratory infection therapy: historical perspectives and current trials. Am J Med 2002; 112(suppl 6A):33S-41S

3 Mascarenhas AR, Seebold JA, Cundy WJ, McGuire T, van Driel ML: Homeopathic remedies for preventing and treating acute respiratory tract infections in children. Cochrane Database Syst Rev 2011;12:CD005974.

4 Monto AS, Fendrick AM, Sarnes MW: Respiratory illness caused by picornavirus infection: a review of clinical outcomes. Clin Ther 2001;23:1615-1627.

5 Gwaltney JM Jr, Hendley JO, Simon G, Jordan WS Jr: Rhinovirus infections in an industrial population. II. Characteristics of illness and antibody response. JAMA 1967;202:494-500.

6 National Institute of Allergy and Infectious Diseases: Common cold. 2012. www.niaid.nih.gov/TOPICS/ COMMONCOLD/Pages/default.aspx.

7 Garibaldi RA: Epidemiology of community-acquired respiratory tract infections in adults. Incidence, etiology, and impact. Am J Med 1985;78(suppl 6B):32-37.

8 Gwaltney JM: Clinical significance and pathogenesis of viral respiratory infections. Am J Med 2002;112(6 suppl 1):13S-18S.

9 Monto AS, Sullivan KM: Acute respiratory illness in the community. Frequency of illness and the agents involved. Epidemiol Infect 1993;110:145-160.

10 World Health Organization: Influenza. Fact sheet no. 211. Revised 2003. www.who.int/mediacentre/ factsheets/2003/fs211/en/.

11 Fashner J, Ericson K, Werner S: Treatment of the common cold in children and adults. Am Fam Physician 2012;86:153-159.

12 Hees K, Scott JD: Prevention and treatment of the common cold in adults. Pharm Times 2008;74:109-116.

13 Simasek M, Blandino DA: Treatment of the common cold. Am Fam Physician 2007;75:515-520.

14 McCaig LF, Besser RE, Hughes JM: Trends in antimicrobial prescribing rates for children and adolescents. JAMA 2002;287:3096-3102.

15 Fisher P: What is homeopathy? An introduction. Fron Biosci (Elite Ed) 2012;4:1669-1682.

16 Flaskamp G, Galuska S: Fieberhafte Erkältungskrankheiten. Erfolgreiche Behandlung mit einem homöopathischen Kombinationspräparat. (Feverish catarrhal illnesses. An effective treatment using a homeopathic combined medication). Der Kassenarzt 1992;49:42-50.

17 Heger M: International outcome study NI001: upper respiratory infections and feverish colds - effectiveness and safety of Nisylen tablets; biometrical report. DHU, Karlsruhe, 1997.
18 Kirkby R, Calabrese C, Kaltman L, Monnier J, Herscu P: Methodological considerations for future controlled influenza treatment trials in complementary and alternative medicine. J Altern Complement Med 2010;16: 275-283.

19 Kirkby R, Herscu P: Homeopathic trial design in influenza treatment. Homeopathy 2010;99:69-75.

20 Barrett B, Brown RL, Mundt MP, Thomas GR, Barlow SK, Highstrom AD, Bahrainian M: Validation of a short form Wisconsin Upper Respiratory Symptom Survey (WURSS-21). Health Qual Life Outcomes 200912;7:76.

21 Papakostas GI, Fava M: Does the probability of receiving placebo influence clinical trial outcome? A metaregression of double-blind, randomized clinical trials in MDD. Eur Neuropsychopharmacol 2009;19:34-40.

22 Fønnebø V, Grimsgaard S, Walach H, Ritenbaugh C, Norheim AJ, MacPherson H, Lewith G, Launsø L, Koithan M, Falkenberg T, Boon H, Aickin M: Researching complementary and alternative treatments - the gatekeepers are not at home. BMC Med Res Methodol 2007;7:7.

23 Steinsbekk A, Fønnebø V, Lewith G, Bentzen N: Homeopathic care for the prevention of upper respiratory tract infections in children: a pragmatic, randomised, controlled trial comparing individualised homeopathic care and waiting-list controls. Complement Ther Med 2005;13:231-238.

24 Supino C: Prevenzione delle infezioni delle alte vie respiratorie in età pediatrica con Omeogriphi ${ }^{\circledR}$. Studio multicentrico controllato. (Omeogriphi ${ }^{\circledR}$ : prevention of upper respiratory infecions in paediatrics. A controlled, multicentric study). La Medicina Biologica 2002;19-23.

25 De Lange de Klerk ES, Blommers J, Kruik DJ, Bezemer PD, Feenstra L: Effect of homoeopathic medicines on daily burden of symptoms in children with recurrent upper respiratory tract infections. BMJ 1994;309:13291332.

26 Jobst D, Altiner A, Wegscheider K, Abholz HH: Helfen intramuskuläre Eigenblutgaben bei chronisch rezidivierenden Infekten der Atemwege? - Fußangeln auf dem Weg einer randomisierten Studie. (Do autologous blood injections help against relapsing upper respiratory infections? - Traps on the way of doing a randomised trial). Z Allg Med 2005;81:258-263.

27 Steinsbekk A, Bentzen N, Fønebø V, Lewith G: Self treatment with one of three self selected, ultramolecular homeopathic medicines for the prevention of upper respiratory tract infections in children. A double-blind randomized placebo controlled trial. Br J Clin Pharmacol 2005;59:447-455.
28 Bornoroni C: Diatesi linfatico-essudativa in trattamento con timosina a dosi omeopatiche. (Treatment of lymph-exudative diathesis with thymosin in homeopathic doses). T.M.A. Italian Journal of Holistic Medicine 1997;11:3-9.

29 Stippig SG: Atemwegserkrankungen bei Kindern Homöopathische und konventionelle Behandlung gleich gut. (Respiratory diseases in children - homeopathic and conventional treatment are equally good). Allgemeinarzt 1996;18:931-936.

30 Chakraborty PS, Lamba CD, Nayak D, John MD Sarkar DB, Poddar A, Arya JS, Raju K, Vivekanand K, Binod Kumar Singh H, Baig H, Prusty AK, Vikram Singh, Nayak C: Effect of individualized homoeopathic treatment in influenza like illness: a multicenter, single blind, randomized, placebo controlled study. Indian Journal of Research in Homoeopathy 2013;7:22-30.

31 Zanasi A, Mazzolini M, Tursi F, Morselli-Labate AM, Paccapelo A, Lecchi M: Homeopathic medicine for acute cough in upper respiratory tract infections and acute bronchitis: a randomized, double-blind, placebocontrolled trial. Pulm Pharmacol Ther 2014;27:102108.

32 Ramchandani NM: Homoeopathic treatment of upper respiratory tract infections in children: evaluation of thirty case series. Complement Ther Clin Pract 2010; 16:101-108.

33 Schmiedel V, Klein P: A complex homeopathic preparation for the symptomatic treatment of upper respiratory infections associated with the common cold: an observational study. Explore (NY) 2006;2:109-114.

34 Schmiedel V, Klein P: A complex homeopathic preparation for the symptomatic treatment of upper respiratory infections associated with the common cold: an observational study. Explore (NY) 2006;2:109-114.

35 Grimaldi-Bensouda L, Bégaud B, Rossignol M, Avouac B, Lert F, Rouillon F, Bénichou J, Massol J, Duru G, Magnier AM, Abenhaim L, Guillemot D: Management of upper respiratory tract infections by different medical practices, including homeopathy, and consumption of antibiotics in primary care: the EPI3 cohort study in France 2007-2008. PLoS One 2014;9:e89990.

36 Sitnikov IG, Moryakova NV: Клинико-патогенетические механизмы действия препарата Инфлюцид при острых респираторных вирусных инфекциях у детей. (Clinical-pathogenetic mechanisms of the action of the drug Influcid in acute respiratory viral infections in children). Infectious Diseases 2010;8:44-47. 